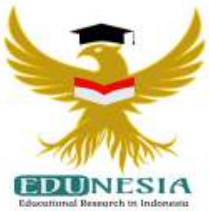

\title{
Peranan Pembelajaran PPKn dalam Menanamkan Nilai-Nilai Karakter Pada Siswa Kelas VIII di Mts Miftahul Ulum Sitiaji
}

\author{
Friska Amelia1; Sarjono2; Ahmad Hariyadi ${ }^{3}$ \\ 1,3Prodi Pendidikan Pancasila dan Kewarganegaraan, IKIP PGRI Bojonegoro, Indonesia. \\ ${ }^{2}$ Prodi Ekonomi, IKIP PGRI Bojonegoro, Indonesia \\ ${ }^{1}$ CorrespondingEmail: afriska002@gmail.com, Phone Number : 0816 xxxx xxxx
}

Article History:

Received: July 26, 2020

Revised: Agust 28, 2020

Accepted: Agust 31, 2020

Published: Nov 01, 2020

Keywords:

Instilling character

values

Role of PPKn learning,

\section{Kata Kunci:}

Menanamkan nilai-nilai karakter

Peranan pembelajaran PPKn,

\section{How to cite:}

Amelia, F., Sarjono., \& Hariyadi, A. (2020). Peranan Pembelajaran PPKN dalam Menanamkan Nilai-Nilai Karakter Pada Siswa Kelas VIII di Mts Miftahul Ulum Sitiaji. Edunesia : Jurnal Ilmiah Pendidikan, 1 (3): 8288

This is an open access article under the CC-BY-NC-ND license

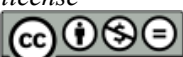

Abstract: The role of the teacher is also very necessary to instill character values in students. That the education of character values is only possible if the values given to the students' life practices are not only cognitive in mind. But also in daily practice the value of habituation activities, extracurricular activities, and attitude of behavior in teaching and learning activities. The objectives of the research are 1). To know the role of PPKn learning in instilling character values in grade VIII MTs Miftahul Ulum Sitiaji Student , 2). To know the process of planting character values through PPKn learning in grade VIII MTs Miftahul Ulum Sitiaji students, This research uses qualitative research. Researcher's data includes interviews, observations and documentation but because of he covid 19 outbreak this observation and documentation cannot be done. The results of this study are 1). The role of Pancasila nd civics educasion very important that involves a lot of character values so that it can make the younger generation better directed, do positive things both not harming oneself or others. 2). The process of instilling character values through learning PPKn is appropriate because it is already in the RPP listed.

Abstrak: peranan guru ppkn sangat diperlukan untuk menanamkan nilainilai karakter pada siswanya. pendidikan nilai-nilai karakter hanya dimungkinkan apabila nilai-nilai diberikan pada praktik-praktik hidup siswa itu sendiri tidak hanya dalam penilian kognitif. Namun juga dalam praktik keseharian yang dinilai dari kegiatan pembiasaan, kegiatan ekstrakulikuler, dan sikap perilakunya dalam kegiatan belajar mengajar. Tujuan penilitian adalah 1).untuk mengetahui peranan pembelajaran PPKn dalam menanamkan nilai-nilai karakter pada siswa kelas VIII di MTs Miftahul Ulum Sitiaji, 2). Untuk mengetahui proses penanaman nilai-nilai karakter melalui pembelajaran PPKn pada siswa kelas VIII di MTs Miftahul Ulum Sitiaji. Penelitian ini menggunakan penelitian kualitatif. Data peneliti yaitu wawancara,observasi dan dokumentasi namun dengan adanya wabah covid 19 ini observasi dan dokumentasi tidak bisa dilakukan.Hasil dari penelitian ini adalah 1). peranan pembelajaran ppkn sangatlah penting dalam pemebelajaran ppkn banyak yang menyangkut nilai-nilai karakter sehingga bisa membuat generasi muda lebih terarah dengan baik,melakukan hal-hal positif baik tidak merugikan diri sendiri ataupun orang lain.2).proses penanaman nilai arakter melalui pemebelajaran PPKn sudah sesuai karena sudah ada dalam RPP yang tercantum. 


\section{A. Pendahuluan}

Pendidikan merupakan salah satu pilar utama yang dapat menjamin kelangsungan hidup suatu bangsa (Hariyadi \& Darmuki, 2019 ). Salah satu alat untuk membangun kesadaran hak asasi manusia para generasi mudanya adalah melalui jalur pendidikan. Pendidikan memiliki hakikat mengajarkan manusia untuk menjunjung tinggi etika, moral, akhlak, budi pekerti serta perilaku manusia dan juga dapat memupuk dan membina kesadaran hak asasi manusia, baik di keluarga, sekolah, maupun masyarakat. Tetapi kenyataanya fenomena penuruna moral yang menggejala dan membudaya di kalangan remaja yang notabene pelajar di Indonesia serta kalangan masyarakat umum dalam bentuk free sex, narkoba, perkelahian, KKN, radikalisme, telah menjadi keprihatinan banyak pihak yang lebih disebabkan oleh hilangnya pendidikan karakter dalam dunia pendidikan (Darmuki, 2013). Di sisi lain dampak negatif globalisasi di kalangan masyarakat Indonesia, khususnya generasi muda telah sebegitu dasyatnya menguasai kehidupan masyarakat Indonesia yang mengakibatkan hilangkan nilai-nilai humanistas. Menurut Bapak Pendiri Negara (the founding fathers) bahwa paling tidak ada tiga tantangan besar yang dihadapi Bangsa Indonesia, Pertama, mendirikan negara yang bersatu dan berdaulat, kedua adalah membangun bangsa, dan ketiga adalah membangun karakter (Muchlas Samani dan Hariyanto, 2011: 1). Penanaman nilai-nilai karakter yang senantiasa dilakukan terhadap anak secara intensif di lingkungan keluarga dan sekolah/ madrasah akan menghasilkan tumbuhnya generasi yang berakhlak atau berkepribadian mulia, sehingga akan mampu mengangkat derajat dan kehormatan bangsa dan negara (Darmuki, 2014).

Menurut Masnur Muslikh (2007: 17) terpuruknya bangsa dan negara Indonesia dewasa ini lebih disebabkan oleh krisis akhlak dan bukan hanya disebabkan oleh krisis ekonomi. Dunia pendidikan kita telah lama melupakan tujuan utama pendidikan yakni mengembangkan pengetahuan, sikap dan keterampilan secara bersamaan dan seimbang. Namun demikian, kondisi ini dapat diantisipasi dengan penanaman nilai-nilai karakter melalui pembiasaan dan pemberian keteladanan di keluarga atau di sekolah dan di masyarakat (Darmuki, 2013). Guru atau orang tua harus menyadari bahwa dirinya merupakan contoh bagi anak didik atau anak-anaknya (Maksudin,2013:81).

Problematika bangsa kita di dunia pendidikan belakangan telah mulai disadari oleh masyarakat dan pemerintah seperti dinyatakan Mendiknas Mohammad Nuh (era pemerintahan Presiden Susilo Bambang Yudhoyono) dalam peringatan Hari Pendidikan Nasional 02 Mei 2011 yang mencanangkan tema peringatan "Pendidikan Karakter sebagai Pilar KebangkitanBangsa" dengan subtema "Raih Prestasi Junjung Tinggi Budi Pekert". Di sinilah kita memahami mengapa pendidikan karakter dengan segala dimensi dan variasinya menjadi sangat mutlak. Karakter yang akan dibangun tidak sekadar kesantunan tetapi juga secara bersamaan membangun karakter yang mampu menumbuhkan kepenasaran intelektual sebagai modal dalam membangun kreativitas dan daya inovasi. Proses pembelajaran tidak hanya melibatkan penguasaan fakta atau konsep sesuatu bidang ilmu saja, namun juga melibatkan perasaan-perasaan yang berkaitan dengan emosi, kasih sayang, benci, dan kerohania. Menurut Winarno (2014: 19) Yaitu pendidikan Pancasiladan dan Kewarganegaraan memiliki dan sejalan dengan tiga fungsi pokok pendidikan Pancasila kewarganegaraan yang demokratis, yakni mengembangkan kecerdasan warga negara (civic intellegence), membina tanggung jawab (civic responsibility) dan mendorong partisipasi warga negara (civic participation). Pendidikan karakter menjadi sebuah keniscayaan ketika melihat realitas generasi muda 
kita yang banyak mengalami berbagai ketimpangan moralitas sebagai output pendidikan formal yang banyak terjadi pengangguran dari lulusan pendidikan dasar dan menengah atas.

Pentingnya moral dan karakter juga diungkapkan oleh Mahatma Gandhi dalam Megawangi (2004:2) Dengan kelahiran dan menjalankan ritual fisik tidak dapat menentukan derajat baik atau buruk seseorang, kualitas karakterlah satu-satunya penentu derajat seseorang. Karakter memiliki makna, nilai dan harga yang sangat besar dalam kehidupan. Karakter adalah sebuah pilihan yang membutuhkan pikiran, keberanian, usaha keras dan penanaman sedikit demi sedikit secara konsisten. Pendidikan Pancasila dan Kewarganegaraan merupakan mata pelajaran yang memfokuskan pada pembentukan warga negara yang memahami dan mampu melaksanakan hak-hak dan kewajibanya untuk menjadi warga negara Indonesia yang cerdas, terampil, dan berkarakter yang diamanatkan oleh Pancasila dan UUD 1945 (Budimansyah, 2008:14). Mata pelajaran Pendidikan Pancasila Kewarganegaraan sebagai mata pelajaran yang berbasis karakter menjadi solusi cerdas untuk menanamkan nilai-nilai karakter pada siswa.

Peranan pembelajaran PPkn sangatlah penting untuk kelangsungan kehidupan bangsa, sebagaimana dalam bangsa kita ini sudah banyaknya siswa di sekolah yang mayoritas tidak memiliki nilai-nilai karakter bahkan sopan santun terhadap orang yang lebih tua. Masih ada yang kurang sopan ketika menjawab sebuah panggilan ataupun memanggil gurunya. Masih banyak yang menggunakan bahasa yang kurang sopan, kurangnya kedisiplinan diri, maka peranan pembelajaran PPKn sangatlah diperlukan untuk membentuk karakter pada siswa tersebut agar lebih baik lagi dan bisa berguna untuk keluarga dan bangsanya. Disamping itu peranan guru PPKn juga sangat diperlukan untuk menanamkan nilai-nilai karakter pada siswanya, sehingga siswa dapat melakukan hal-hal yang lebih positif dan bermanfaat untuk diri mereka sendiri.

Pengertian peranan menurut Soerjono Soekanto (2002:243), yaitu peran merupakan aspek dinamis kedudukan (status), apabila seseorang melaksanakan hak dan kewajibannya sesuai dengan kedudukannya, maka ia menjalankan suatu peranan. Menurut Samsuri (2011:28), Pendidikan Pancasila dan Kewarganegaraan dapat diartikan sebuah cara untuk mempersiapkan generasi penerus bangsa demi menjadi seorang warga Negara yang memiliki kecakapan, dan pengetahuan serta nilai-nilai pancasila untuk berpartisipasi aktif di dalam masyarakat dan Negara. Darmuki \& Hariyadi (2019: 280) menyatakan bahwa belajar merupakan perubahan individu yang disebabkan oleh pengalaman ,sehingga pembelajaran adalah suatu perubahan yang diperoleh dari pengalaman.

Pembelajaran sama artinya dengan kegiatan mengajar. Kegiatan mengajar dilakukan oleh guru untuk menyampaikan pengetahuan kepada siswa. Pembelajaran merupakan suatu sistem, yang terdiri dari berbagai komponen yang saling berhubungan dan saling mempengaruhi satu dengan yang lain.

Dalam pembelajaran PPKn Menurut Adisusilo (2012:82-83), yang dapat dilakukan oleh guru yaitu sebagai berikut: a) Guru harus mengubah paradigma dari pengajar menjadi pendidik. b) Dalam setiap pembelajaran atau tatap muka, guru menunjukkan bahwa "di balik" materi yang dipelajari, minimal ada satu nilai kehidupan yang baik bagi siswa untuk diketahui, dipikirkan, direnungkan dan diyakini dan dipraktikan sebagai hal yang baik dan benar sehingga mendorongnya untuk melaksanakan dalam kehidupannya, c) Guru memberikan penanaman mulai dengan nilai-nilai yang elementer, relevan, dan konstektual, misalnya guru PPKn menekankan nilai, kejujuran, kemanusiaan, penghormatan terhadap sesama/rasa hormat, kedisplinan, ketertiban, kepedulian dan lain-lain dalam kehidupan sehari-hari, dan d) Nilai-nilai tertentu itu terus-menerus 
diingatkan kepada siswa,agar siswa biasa mepraktikannya dan guru mencoba memberi contoh konkret.

Nilai-nilai Karakter adalah sikap dan perilaku yang didasarkan dalam norma dimasyarakat,yang mencakup asperk-aspek dialamnya yaitu aspek sprilitual, aspek personal/kepribadian, aspek sosial,dan aspek lingkungan (Direktorat pembinaan PAUD, 2012 : 4).Nilai adalah suatu penghargaan atau kualitas terhadap sesuatu atau hal, yang dapat dasar penentu tingkah alaku seseorang, karena sesuatu hal itu menyenangkan (pleasant) dan memuaskan (satifying).

Nilai-nilai karakter yang perlu ditanamkan kepada anak-anak adalah nilai-nilai universal pada seluruh agama, tradisi dan budaya pasti menjunjung tinggi nilai-nilai tersebut. Nilai-nilai universal ini harus dapat menjadi perekat bagi seluruh anggota masyarakat ,meskipun berbeda latar belakang budaya, suku dan agama.Berdasarkan keempat sumber nilai di atas, Kementerian Pendidikan Nasional (2010:25-30).

\section{B. Metode}

Jenis penelitian yang digunakan dalam penelitian ini adalah kualitatif yang bersifat deskriptif, yaitu penelitian yang dilakukan untuk kmemperoleh gambaran situasi dan kejadian-kejadian secara konkret tentang keadaan objek atau suatu masalah.

Penelitian kualitatif adalah tradisi tertentu dalam ilmu pengetahuan sosial yang secara fundamental bergantung dari pengamatan pada manusia, baik dalam kawasannya maupun dalam peristilahannya (Moleong, 2004: 4). Di sisi lain, penelitian kualitatif adalah pengumpulan data pada suatu latar ilmiah, dengan menggunakan metode alamiah dengan menggunakan metode alamiah dan dilakukan oleh orang/peneliti yang tertarik secara alamiah (Moleong, 2004: 5).

Penelitian kualitatif adalah penelitian yang menggunakan latar alamiah dengan maksud mengartikan fenomena yang terjadi dan dilakukan dengan jalan melibatkan berbagai metode yang ada (Moleong, 2004: 5). Pendekatan ini diharapkan bahwa dapat mengetahui bagaimana peranan pembelajaran PPKn dalam menanamkan nilai-nilai Karakter yang dilakukan di MTs Miftahul Ulum Sitiaji dan bagaimana penanaman nilainilai karakter melalui pembelajaran PPKn.

\section{Hasil dan Pembahasan}

Peranan pembelajaran PPKn dalam menanamkan nilai-nilai karakter di Madrasah ini sangatlah penting karena dalam pembelajaran PPKn banyak yang menyangkut nilainilai karakter sehingga bisa membuat generasi muda lebih terarah dengan baik, melakukan hal-hal positif baik tidak merugikan diri sendiri ataupun orang lain selain itu sangatlah penting dalam kehidupan di dalam lingkungan sekolah maupun di dalam lingkungan masyarakat, agar siswa tidak melakukan hal-hal yang tidak di inginkan yang terkait dengan karakter yang bisa merusak jiwa atau moral mereka sendiri.

Proses penanaman nilai-nilai karakter melalui pembelajaran PPKn di madrasah sudah sesuai, karena sudah sesuai dengan nilai-nilai karakter yang dalam materi pembelajaran PPKn sehingga siswa bisa menerapkan dengan baik dan sesuai dengan krakter yang bisa membuat mereka melakukan hal-hal yang positif sehingga penanaman nilai-nialai karakter dapat tertanam. Data hasil penelitian ini diperoleh dari wawancara kepada guru PPKn dan siswaVIII MTs Miftahul Ulum Sitiaji melalui google forms, berhubung keadaan dengan adanya wabah covid 19 observasi dan dokumentasi 
secara langsung tidak langsung. Sebagaimana hasil wawan cara kepada guru PPKn MTs Miftahu Ulum Sitiaji

Peranan pembelajaran PPKn dalam menanamkan niali-nilai karakter pada siswa kelas VIII MTs Miftahul Ulum Sitiaji mencakup nilai-nilai karakter yang tercantum dalam pembelajaran PPKn.Peranan pembelajaran PPKn dalam menanamkan nilai-nilai karakter sangat berperan penting. Karena dalam pembelajaran PPKn banyak yang menyangkut nilai-nilai karakter sehingga bisa membuat generasi muda lebih terarah dengan baik, melakukan hal-hal positif baik tidak merugikan diri sendiri ataupun orang lain. Selain itu ,nilai-nilai karakter adalah sebagai pedoman utuk menjadikan diri agar lebih baik dan bisa menjadi orang yang bermanfaat untuk diri sendiri maupun orang lain,selain itu nilai-nilai krakter adalah sebagai pagar diri dari hal-hal yang buruk contohnya pada saat di sekolah tidak disiplin melanggar peraturan sekolah seperti mencontek, membolos, baju dikeluarkan atau tidak sopan saat berbicara dengan guru, jadi pembelajaran PPKn sangatlah penting untuk menanamkan nilai-nilai krakter agar dalam kehidupan di dalam lingkungan sekolah maupun di dalam lingkungan masyarakat siswa tidak melakukan hal-hal yang tidak di inginkan. Atau tidak menaati peraturan yang ada sehingga siswa diharapkan untuk lebih jera dengan sanksi,agar kedisiplinan bisa selalu dilakukan.

Pernyataan tersebut sesuai dengan Kementerian Pendidikan Nasional (2010:25-30), Nilai-nilai karakter yang perlu ditanamkan kepada anak-anak adalah nilai-nilai universal yang mana seluruh agama, tradisi dan budaya pasti menjunjung tinggi nilai-nilai tersebut. Nilai-nilai universal ini harus dapat menjadi perekat bagi seluruh anggota masyarakat walaupun berbeda latar belakang budaya, suku dan agama.Berdasarkan keempat sumber nilai di atas,menyebutkan nilai-nilai untuk pendidikan budaya dan karakter bangsa sebagai berikut:1. Religius, 2) jujur, 3) disiplin, 4) demokratis, 5) cinta tanah air dan lain lain.

Dari hasil wawancara tersebut peranan pembelajaran ppkn sangatlah penting dalam pembelajaran ppkn banyak yang menyangkut nilai-nilai karakter. Agar bisa membuat generasi muda lebih terarah dengan baik, melakukan hal-hal positif baik tidak merugikan diri sendiri ataupun orang lain selain itu juga penting dalam kehidupan di dalam lingkungan sekolah maupun di dalam lingkungan masyarakat.

Hal tersebut sesuai dengan pendapat Puspitasari (2016: 46). Pendidikan karakter pada intinya bertujuan membentuk bangsa yang tangguh, kompetitif, berakhlak mulia, bermoral, bertoleransi, bergotong royong, berjiwa patriotik, berkembang dinamis, berorientasi ilmu pengetahuan dan teknologi yang semuanya dijiwai oleh iman dan takwa kepada Tuhan Yang Maha Esa berdasarkan Pancasila. Proses penanaman nilai-nialai karakter melalui pemebalajaran PPKn sangatlah baik sesuai dengan rencana pelaksanaan pembelajaran (RPP), sehingga guru bukan hanya menjelaskan tentang nilai-nilai karakter yang terkandung dalam materi melainkan guru juga memberikan contoh secara langsung misalnya ada sampah di dalam kelas siswa harus mengambil dan membuang sampah tersebut pada tempatnya atau merapikan baju yang keluar atau memeriksa ikat pinggang, namum masih saja ada siswa yang tidak taat pada ketentuan sekolahan contohnya melanggar kedisplinan seperti: seragam dikeluarkan tidak memakai ikat pinggang.

Sebagaimana hasil wawancara peneliti dengan guru PPKn melalui google forms dan wawancara via whatsapp penanaman pembelajaran PPKn sudah sesuai dengan materi pembelajaran, dan bagi siswa yang melakukan tindakan yang tidak sesuai dengan peratuaran sekolah maka siswa diberikan teguran atau pemahaman secara langsung. 
Proses penanaman nilai-nilai karakter dalam pembelajaran PPKn sudah sesuai,karena sudah sesuai dengan nialai-niali karakter dalam materi pembelajaran PPKn termuat dari RPP dalam kegiatan inti, sehingga siswa bisa menerapkan dengan baik dan sesuai dengan krakter yang bisa membuat mereka melakukan hal-hal yang positif sehingga penanaman nilai-nilai karakter dapat tertanam dengan memberikan contoh yang baik kepada peserta didik, serta melakukan hal-hal yang positif baik saat mengajar di kelas maupun lingkungan sekolah, terutama nilai kedisiplinan karena didalam mengajarkan hal yang baik, seperti dengan membuang sampah pada tempatnya,merapikan pakaian yang masih keluar dan tidak mencontek saat ulangan belangsung, namun banyak juga siswa-siswi yang masih melanggar peraturan sekoalah seperti mencontek,baju keluar dan tidak memakai ikat pinggang, dan adanya ekstrakurikuler berbasis pendidikan karakter seperti pemilihan ketua osis yaitu sebagai nilai demokratis, jika ada siswa yang melanggar atau melakukan tindakan yang melanggar kedisiplinan seperti baju dikelaukan, tidak pakai ikat pinggang guru akan memberikan peneguran dan arahan serta membimbinganya supaya dia tidak melakukan lagi kesalahan-kesalahan yang sama dan yang terakhir hukuman apabila melakukan sesuatu yang merugikan temannya.

\section{Kesimpulan}

Dari jawaban narasumber diatas dapat disimpulkan bahwa proses penanaman nilai-nilai karakter melalui pemebelajaran PPKn sudah sesuai karena sudah ada dalam RPP yang tercantum nilai-nilai karakter seperti jujur,tanggung jawab,menghormati guru, dan demokratis sesuai dalam pembelajaran PPKn berlangsung meskipun ada beberapa siswa yang masih melakukan pelanggaran peraturan sehingga masih butuh penananam niali-niilai karakter secara langsung dan peneguran agar siswa tidak mengulangi kesalahan yang sama.

Kepribadian siswa ada yang berbeda-beda sehingga proses penanaman nilai-nilai karakter melalui pemebelajaran PPKn sangatlah diperlukan sehingga dapat membangun karakter yang baik dan positif. Pendidikan Pancasila dan Kewarganegaraan diajarkan di sekolah tidak hanya dinilai dari aspek kognitif saja dan dapat dilihat secara langsung, akan tetapi lebih mengutamakan tindakan dengan mengimplementasikan nilai-nilai karakter pada siswa melalui pembelajaran PPKn.

\section{UcapanTerimakasih}

Terima kasih kepada Allah SWT yang telah memberika nikmat kesehatan,dan untuk kedua orang tua terima kasih atas segala support dan fasilitasnya dan terimakasih untuk dosen pembimbing bapak Dr.Hariyadi, M. Pd Atas segala dedikasi yang diberikan semoga semua ini bermanfaat untuk orang-orang yang membaca.

\section{Daftar Pustaka}

Adisusilo, S. 2012. Pembelajaran Nilai Karakter. Jakarta: PT. Raja Grafiando persada.

Budimansyah, Dasim dan Karim. 2008. PKn dan Masyarakat Multikultural. Bandung: Universitas Pendidikan Indonesia. 
Hariyadi, A. \& Darmuki, A. 2019. Eksperimentasi Model Pembelajaran Jucama Ditinjau Dari Gaya Belajar Terhadap Prestasi Belajar Mahasiswa Mata Kuliah Berbicara Di Prodi PBSI IKIP PGRI Bojonegoro. Kredo. 3(1), 62-72.

Darmuki, A. 2014. Pengintegrasian Pendidikan Budaya dan Karakter Bangsa dalam Pengajaran Matakuliah Bahasa Indonesia di Perguruan Tinggi IKIP PGRI Bojonegoro. Seminar Nasional AJPBSI. Vol. 3(1), 79-82.

Darmuki, A. 2013. Pembelajaran Menulis Puisi dalam Pembentukan karakter Berdasarkan Kurikulum 2013. Seminar Nasional Inovasi PBSI dalam Kurikulum 2013. Vol. 1, 34-40.

Hariyadi, A. \& Darmuki, A. 2019. Prestasi dan Motivasi Belajar dengan Konsep Diri. Prosiding Seminar Nasional Penguatan Muatan Lokal Bahasa Daerah sebagai Pondasi Pendidikan Karakter Generasi Milenial. PGSD UMK 2019, 280-286.

Kementerian Pendidikan Nasional Badan Penelitian dan Pengembangan Pusat Kurikulum. 2010. Pengembangan Pendidikan Budaya Dan Karakter Bangsa. Jakarta.

Maksudin. 2013. Pendidikan Karakter Non-Dikotomik. Yogyakarta: Pustaka Pelajar

Megawangi, R. 2004. Pendidikan Karakter. Jakarta: BPMIGAS.

Moleong, J. L. 2004. Metodologi Penelitian suatu pendekatan. Bandung Remaja Rosdakarya.

Mulyana, R. 2004. Mengartikulasikan Pendidikan Nilai. Bandung: Alfabeta

Muslich, M. 2007. KTSP Pembelajaran Berbasis Kompetensi dan Kontekstual. Jakarta: Bumi Aksara.

Pusat Departemen Pendidikan Nasional. 2005. Kamus Besar Bahasa Indonesia.Jakarta: Balai Pustaka.

Puspitasari, R. 2016. "Penanaman Nilai Karakter Peduli Lingkungan dalam Muatan Enveromental Education pada Pembelajaran IPS di Mi Darul Hikam kota Cirebon ". Jurnal Al Ibtida.Vol. 2, No. 1. 39-56.

Samsuri. 2011. Pendidikan Kewarganegaraan sebagai Wahan Membangun Karakter Bangsa. Yogyakarta: UNY Pres.

Samani, M, H. 2012. Peandidikan Karakter. Bandung: PT Remaja Rosdakarya.

Soekanto, S. 2002. Teori Peranan. Bumi Aksara . Jakarta.

Winarno. 2014. Pembelajaran Pendidikan Kewarganegaraan. Jakarta. Bumi Aksara. 